
FciDioc

International Journal of Clinical \& Experimental Otolaryngology (IJCEO)

ISSN 2572-732X

\title{
Multicentric Thyroid Carcinoma: Epidemiological and Histological Analysis in a Cancer Reference Hospital
}

Research Article

Goulart RN, Medina Santos LR*, Borba C, Priscila A

Supervisor for the H\&N Surgery Residency Program CEPON, Florianopolis, SC, Brazil.

\section{Abstract}

Background: The incidence of thyroid cancer has been increasing in recent years. The extent of thyroidectomy to treat these patients has been largely discussed. Besides, the study of multifocality of thyroid cancer becomes important, especially due to the inconsistency in the literature on related factors, such as recurrence, metastasis and prognosis. The main objective of this study is to describe and analyze the epidemiological and histological factors associated with multicentric thyroid carcinoma.

Method: Cross-sectional, retrospective study collecting histological data from all patients who underwent total thyroidectomy for treatment of thyroid cancer in a cancer reference hospital, between January 2013 and December 2014.

Results: 88 patients with histological diagnosis of thyroid cancer were recruited. Females accounted for $87.5 \%$ of cases, with mean age of 47.6 years old. Papillary carcinoma was diagnosed in $88 \%$ of patients. Tumors smaller than $2 \mathrm{~cm}$ accounted for $65.8 \%$ of cases, most of them non encapsulated (58\%). One out of three patients had more than one focus of thyroid cancer. Lymph node metastasis were reported in $20 \%$ of patients. The presence of goiter in the specimen and non encapsulated tumors were significantly associated with multifocal thyroid cancer.

Conclusion: Two or more thyroid cancer foci were reported in $33 \%$ of patients and were significantly associated with the absence of capsule around thyroid tumors $(68.9 \%, \mathrm{n}=20, \mathrm{p}=0.04)$ and the presence of goiter $(65.5 \%, \mathrm{n}=19, \mathrm{p}=0.01)$. The presence of tumor in the opposite lobe was identified in $24 \%$ of patients, in our series.

Keywords: Thyroid Cancer; Multicentric; Thyroidectomy.

\section{Introduction}

Thyroid cancer is the most prevalent endocrine neoplasm, corresponding to $0.5 \%-1.5 \%$ of all types of cancer. Data in the literature report an increase of 2.9 times in the incidence of papillary thyroid cancer in the United States, between 1973 and 2002.

The American Cancer Society estimates that in 2008 were diagnosed over 37,000 new cases of thyroid cancer in the United States, with a mortality rate around 1,600 cases [1]. In Brazil, according to INCA data (Instituto Nacional de Câncer - National Cancer Institute), it is estimated that in 2016 will be diagnosed more than 6,950 new cases of thyroid cancer [2].
The papillary thyroid carcinoma and follicular carcinoma are grouped as well differentiated thyroid carcinomas and, together, account for more than $94 \%$ of all malignant tumors of the gland. The incidence of thyroid cancer is increasing all over the world, mainly because of better access to diagnostic methods (image and cytology) and awareness, with particular increase in detection of

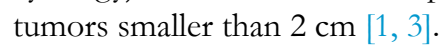

There is a long-standing debate on the extension of the thyroidectomy for small lesions of well-differentiated thyroid carcinoma. Consensus guidelines suggest that low-risk patients with tumors smaller than $1 \mathrm{~cm}$, unique, without suspicious cervical lymph nodes, may be candidates to a less extensive surgery, such as thyroid lobectomy. These same guidelines recommend total thyroidectomy for tumors larger than $1 \mathrm{~cm}$ in diameter or in

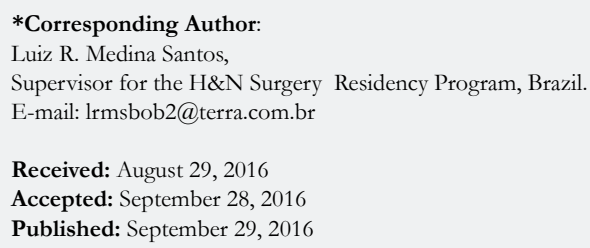

Citation: Goulart RN, Medina Santos LR, Borba C, Priscila A (2016) Multicentric Thyroid Carcinoma: Epidemiological and Histological Analysis in a Cancer Reference Hospital. Int J Clin Exp Otolaryngol. 2(4), 35-41. doi: http://dx.doi.org/10.19070/2572-732X-160007

Copyright: Medina Santos LR ${ }^{\circ}$ 2016. This is an open-access article distributed under the terms of the Creative Commons Attribution License, which permits unrestricted use, distribution and reproduction in any medium, provided the original author and source are credited. 
patients from high-risk group $[4,5]$.

Among the main considerations for partial thyroidectomy, the low level of tumor multifocality estimated in the thyroid gland and, more specifically, in the contralateral lobe, is an important fact.

The prevalence of thyroid cancer multifocality is not clear in the literature and varies between $18 \%$ and $87 \%$ [6-12]. The justification for these inaccurate rates may be related to some factors: It is known that a significant increase in the number of neoplastic foci is found when the thyroid gland is systematically sectioned and examined during the histological analysis, when compared with cases submitted only to representative sampling (60\% vs. $37 \%$ ) [13]. In addition, epidemiological factors, ethnic, geographical and environmental factors can also be involved and have been defended as characteristics associated with thyroid cancer multicentricity [14-17].

The multifocality can be associated with large foci (clinically evident) or, more often, the multiple foci of microcarcinomas (tumors smaller than $1 \mathrm{~cm}$ ). These foci can be found in a single thyroid lobe (unilateral disease) or in both lobes (bilateral disease) $[18,19]$.

The diagnosis of an unilateral multifocal disease of the thyroid gland does not discard the presence of contralateral cancer, which may occur in 13 to $71 \%$ of cases. Although the thyroid carcinoma multicentricity is a relatively common situation, molecular pathogenesis, the prognostic relevance and the best treatment/ monitoring of these patients are still controversial [13, 19-21].

Some studies have established a clear association between multifocal lesions and local recurrence, regional lymph node involvement and distant metastasis, justifying a more aggressive approach to treatment of patients with thyroid cancer $[6,22]$.

For this reason, the objective of this study was to describe and analyze the epidemiological and histological factors associated with multicentric thyroid carcinoma.

\section{Methods}

A retrospective analysis were undertaken of all histopathological results of patients who were surgically treated for cancer of the thyroid, treated at Oncologic Research Center - CEPON, in Florianopolis, Santa Catarina - Brazil (reference State Hospital in cancer), from January 2013 to December 2014.

The variables analyzed were gender, age, histological type, tumor size, presence of a capsule around the tumor, extra thyroid extension, vascular invasion, angiolymphatic invasion, neural invasion or perineural invasion, presence of multifocality, quantity of foci, location, presence of goiter and thyroiditis associated, as well as presence of lymph node metastasis.

The technique of analysis of the surgical specimen recommended by the Pathology Service in our Institution is the representative evaluation (by sampling) of the thyroid gland, including more tissues to be examined as suspicious either macro or microscopically.

The quantitative variables were calculated with averages and standard deviations (SD), minimum and maximum values, and median values. The categorical variables were described through their absolute frequency (n) and relative (\%). Associations between categorical variables were investigated by the Pearson chi-square test or Fisher exact test, when appropriate. The analyzes were performed by the Microsoft Excel and EpiInfo 6.04 app.

\section{Results}

A total of 132 histological reports for thyroid gland were evaluated and the diagnosis of cancer was present in 88 specimens of patients, composing the population of our study. From this group, only one patient was submitted to lobectomy for treatment of thyroid cancer, with agenesis or involution of the left lobe. The remainder received, as minimal form of surgical treatment for thyroid cancer, total thyroidectomy.

The female gender corresponded to $87.5 \%$ of the assessed patients. The age of the patients ranged from 20 to 76 years, with an average of 47.6 years. When grouped, most of the patients were aged between $41-60$ years $(58 \%, n=52)$. (Table 01$)$.

In relation to the histological types of thyroid cancer, the papillary carcinoma was the most prevalent, described in $88 \%$ of cases $(n=77)$, followed by follicular carcinoma in $8 \%(n=7)$, both corresponding to $95.4 \%(\mathrm{n}=84)$ of well-differentiated thyroid

Table 1. Demographic data for patients in the study.

\begin{tabular}{|c|c|c|}
\hline & $\%$ & $\mathrm{n}$ \\
\hline Gender & & \\
\hline Female & 87.5 & 77 \\
\hline Male & 12.5 & 11 \\
\hline & 100 & 88 \\
\hline Age (years) & & \\
\hline$\leq 19$ & - & - \\
\hline $20-40$ & 28 & 24 \\
\hline $41-60$ & 58 & 52 \\
\hline$\geq 61$ & 14 & 12 \\
\hline & 100 & 88 \\
\hline
\end{tabular}


carcinomas, in our series (Figure 01).

Tumors smaller than $2 \mathrm{~cm}$ (T1) were present in $65.8 \%$ of the patients ( $n=58)$, being microcarcinomas in $35.2 \%(n=31)$. Lesions between 2 and $4 \mathrm{~cm}$ (T2) corresponded to $27.3 \%(\mathrm{n}=24)$ and larger than $4 \mathrm{~cm}$ neoplasms in $6.9 \%(\mathrm{n}=6)$. (Table 02).

In relation to the presence of a capsule around thyroid tumors, after disregarding the patients that did not present this as described in their reports, it was seen that in $42 \%$ of patients $(n=32)$ the lesion was encapsulated or partially encapsulated.

The evidence of thyroid capsular invasion by cancer was present in 28 patients $(32.5 \%)$. In two cases this information was not described in the reports.

Malignant neoplasms of the thyroid gland without vascular invasion were present in the majority of patients in this study $(75 \%, \mathrm{n}=48)$, disregarding the cases in which this data was not described $(n=24)$. In relation to the invasion of lymphatic tissue, it was seen that in $65 \%$ of cases $(n=54)$ the lesions did not have angiolymphatic invasion. About neural and/or perineural invasion, many pathological reports did not mention this fact $(n=34)$. After that disregard, $92.6 \%$ of patients had no neural invasion by the thyroid cancer. The majority of thyroid tumors studied presented no extension to adjacent tissues $(84 \%, \mathrm{n}=74)$.

The cancer of the thyroid gland was present in the left lobe in $42 \%$ of patients $(n=37)$, followed by the right lobe in $33 \%(n=29)$, bilateral in $23.9 \%(\mathrm{n}=21)$ and one in the isthmus. The histological diagnosis of goiter associated with thyroid cancer was present in the majority of patients $(54.3 \%, \mathrm{n}=44)$. In seven cases this data was not described in the pathological report.

After disregard the absence of data, the association of thyroid cancer and thyroiditis was described in 26 patients (35.6\%). The cervical lymph nodal involvement by thyroid cancer, either in the central or lateral compartment, was described in $20 \%(n=18)$ of the patients.

One in three patients evaluated in this study had more than one focus of thyroid cancer $(33 \%, n=29)$. The presence of two foci was identified in $72.4 \%$ of the patients $(n=21)$ (multifocal disease).
After comparing the variables described with the presence of multifocality of the thyroid cancer, it was observed that the presence of two or more foci of thyroid cancer was more prevalent in females $(79.3 \%, \mathrm{n}=23)$. Regarding 11 men with thyroid cancer in this study, $54.5 \%(\mathrm{n}=6)$ presented multifocal disease. In relation to age, $41.6 \%$ of patients above 61 years of age had more than one focus of malignant neoplasm in the thyroid.

Regarding to the histological type, the majority of patients with more than one focus of disease presented thyroid papillary carcinoma $(93 \%, n=27)$. A patient with medullary carcinoma and another with the insular variant of follicular carcinoma had more than one focus of disease in the thyroid gland, being, in both situations, papillary carcinoma on the second focus. All patients with follicular carcinoma presented only one focus of tumor.

In most cases of multifocal disease $(69 \%, n=20)$, the size of the dominant focus of cancer was smaller than $2 \mathrm{~cm}$, being microcarcinomas in $31.2 \%$ of the cases $(n=9)$.

Regarding to thyroid capsular invasion, $41 \%$ of the cases of multicentricity were associated with extra thyroid extension. In $48.2 \%$ of the patients with extra thyroid extension there were more than one focus of disease. Only $13.7 \%$ of the patients with multifocal disease showed vascular invasion. $37.9 \%$ of the cases of multicentricity had angiolymphatic invasion and none showed neural invasion. The invasion of adjacent tissues was present in $24.1 \%$ of multifocal tumors.

The great majority of patients with multifocal disease had only two foci of thyroid cancer $(72.4 \%, n=21)$, and of these, only one patient presented the second focus of tumor greater than $1 \mathrm{~cm}$ (pT1b). The others presented microcarcinoma as second focus of cancer. The presence of contralateral tumor to the primary thyroid cancer was evidenced in $72.4 \%(n=21)$ of the cases of multicentric disease. Therefore, the rate of contra laterality in our patients was $24 \%$.

Thyroiditis was associated to multicentric disease in $24.1 \%$ of cases. Only $15.2 \%$ of the patients with multifocal disease had lymph node metastasis. In this study, in a statistically significant way, $68.9 \%(n=20, p=0.04)$ of patients with multifocal disease

Figure 1. Prevalence of histological types for thyroid cancer.

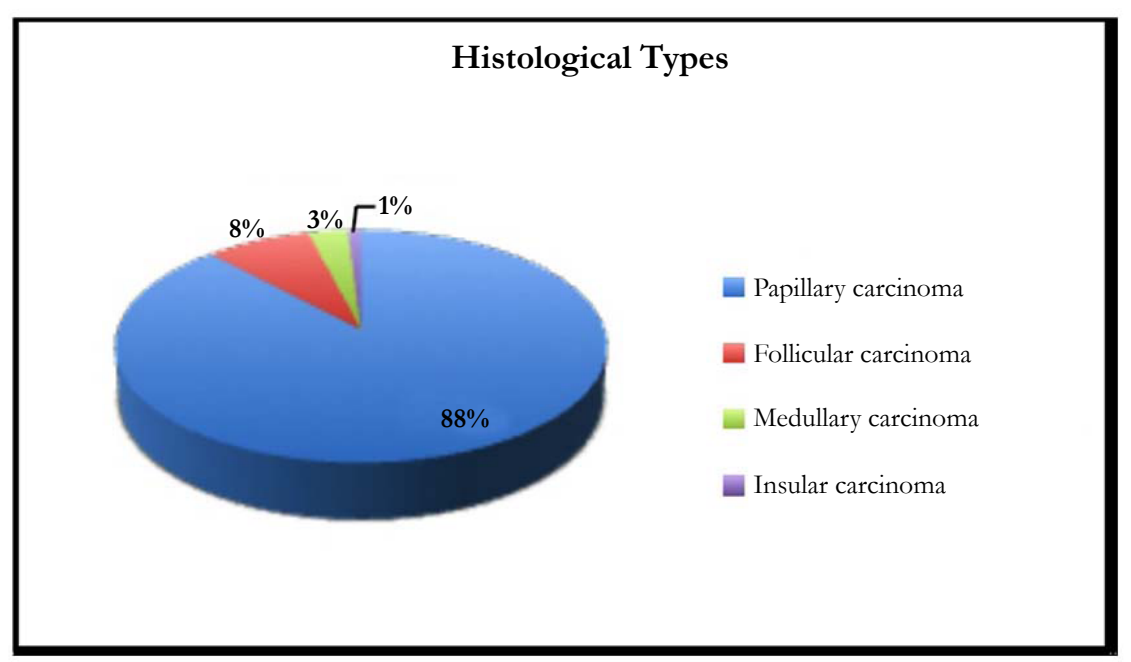


Table 2. Description of histological findings of thyroid cancer.

\begin{tabular}{|c|c|c|}
\hline & $\%$ & $\mathbf{n}$ \\
\hline \multicolumn{3}{|l|}{ Size } \\
\hline \multicolumn{3}{|l|}{$\mathrm{T} 1$} \\
\hline T1a & 35.2 & 31 \\
\hline $\mathrm{T} 1 \mathrm{~b}$ & 30.6 & 27 \\
\hline $\mathrm{T} 2$ & 27.3 & 24 \\
\hline \multirow[t]{2}{*}{$\geq \mathrm{T} 3$} & 6.9 & 6 \\
\hline & 100 & 88 \\
\hline \multicolumn{3}{|l|}{ Tumor capsule } \\
\hline $\begin{array}{l}\text { Encapsulated or } \\
\text { partially encapsulated }\end{array}$ & 42 & 32 \\
\hline \multirow[t]{2}{*}{ Non encapsulated } & 58 & 44 \\
\hline & 100 & 76 \\
\hline \multicolumn{3}{|l|}{ Thyroid capsular invasion } \\
\hline Yes & 32.5 & 28 \\
\hline \multirow[t]{2}{*}{ No } & 67.5 & 58 \\
\hline & 100 & 86 \\
\hline \multicolumn{3}{|l|}{ Extension to adjacent tissues } \\
\hline Yes & 16 & 14 \\
\hline \multirow[t]{2}{*}{$\mathrm{No}$} & 84 & 74 \\
\hline & 100 & 88 \\
\hline \multicolumn{3}{|l|}{ Multicentricity } \\
\hline Yes & 33 & 29 \\
\hline \multirow[t]{2}{*}{ No } & 67 & 59 \\
\hline & 100 & 88 \\
\hline \multicolumn{3}{|l|}{ Number of foci } \\
\hline 2 & 72.4 & 21 \\
\hline 3 & 17.3 & 5 \\
\hline \multirow{2}{*}{$\geq 4$} & 10.3 & 3 \\
\hline & 100 & 29 \\
\hline \multicolumn{3}{|l|}{ Location } \\
\hline Left lobe & 42 & 37 \\
\hline Right lobe & 33 & 29 \\
\hline Isthmus & 1.1 & 1 \\
\hline \multirow[t]{2}{*}{ Bilateral } & 23.9 & 21 \\
\hline & 100 & 88 \\
\hline \multicolumn{3}{|l|}{ Goiter } \\
\hline Yes & 54.3 & 44 \\
\hline \multirow[t]{2}{*}{ No } & 45.7 & 37 \\
\hline & 100 & 81 \\
\hline \multicolumn{3}{|l|}{ Thyroiditis } \\
\hline Yes & 35.6 & 26 \\
\hline \multirow[t]{2}{*}{ No } & 64.4 & 47 \\
\hline & 100 & 73 \\
\hline \multicolumn{3}{|l|}{ Lymph node metastasis } \\
\hline Yes & 20 & 18 \\
\hline \multirow[t]{2}{*}{ No } & 80 & 70 \\
\hline & 100 & 88 \\
\hline
\end{tabular}

had no capsule delimiting the thyroid tumors.

Comparing the multicentricity and the presence of goiter, it was evidenced a statistically significant association $(p=0.01)$, when $65.5 \%$ of the patients with multifocal disease had histological diagnosis of goiter (Table 03).

The analysis of our data evidenced that the presence of lymph node metastasis was associated, in a statistically significant way, with tumors larger than $4 \mathrm{~cm}(66.6 \%, \mathrm{n}=4, \mathrm{p}=0.007)$, not encapsulated tumors $(77.7 \%, \mathrm{n}=14, \mathrm{p}=0.03)$, thyroid capsular invasion $(61.1 \%, \mathrm{n}=11, \mathrm{p}=0.01)$ and presence of angiolymphatic invasion $(77.7 \%, \mathrm{n}=14, \mathrm{p}=0.03)$. The absence of invasion by the tumor of adjacent thyroid tissues, was associated with the absence of cervical lymph node involvement $(90 \%, \mathrm{n}=63, \mathrm{p}=0.001)$.

\section{Discussion}

The debate about the extent of the ideal surgery for thyroid microcarcinomas is still ongoing. The guidelines presented by Haugen et al., [5] recommend the total thyroidectomy for all patients with tumors $\geq 1 \mathrm{~cm}$. This recommendation is based, among other considerations, in the contralateral disease risk [23]. 
Table 3. Factors associated to multicentricity in thyroid cancer.

\begin{tabular}{|c|c|c|c|}
\hline & $\%$ & $\mathrm{n}$ & P value \\
\hline \multicolumn{4}{|l|}{ Age (years) } \\
\hline$\leq 19$ & - & - & \\
\hline 20 a 40 & $33.3(100)$ & 8 & \\
\hline 41 a 60 & $30.7(100)$ & 16 & \\
\hline \multirow[t]{2}{*}{$\geq 61$} & $41.6(100)$ & 5 & \\
\hline & & 29 & $\mathrm{p}=0.52$ \\
\hline \multicolumn{4}{|l|}{ Histological types } \\
\hline Papillary carcinoma & 93 & 27 & \\
\hline Medullary carcinoma & 3.5 & 1 & \\
\hline \multirow{2}{*}{ Follicular insular carcinoma } & 3.5 & 1 & \\
\hline & 100 & 29 & $\mathrm{p}=0.08$ \\
\hline \multicolumn{4}{|l|}{ Size } \\
\hline \multicolumn{4}{|l|}{ T1 } \\
\hline T1a & 31.2 & 9 & \\
\hline T1b & 37.8 & 11 & \\
\hline $\mathrm{T} 2$ & 24 & 7 & \\
\hline \multirow[t]{2}{*}{$>\mathrm{T} 3$} & 7 & 2 & \\
\hline & 100 & 29 & $\mathrm{p}=0.76$ \\
\hline \multicolumn{4}{|l|}{ Tumor capsule } \\
\hline Encapsulated & 31.1 & 9 & \\
\hline \multirow[t]{2}{*}{ Not encapsulated } & 68.9 & 20 & \\
\hline & 100 & 29 & $\mathrm{p}=0.04$ \\
\hline \multicolumn{4}{|l|}{ Thyroid capsular invasion } \\
\hline Yes & 41 & 12 & \\
\hline \multirow[t]{2}{*}{ No } & 59 & 17 & \\
\hline & 100 & 29 & $\mathrm{p}=0.12$ \\
\hline \multicolumn{4}{|l|}{ Adjacent tissues invasion } \\
\hline Yes & 24.1 & 7 & \\
\hline \multirow[t]{2}{*}{ No } & 75.9 & 22 & \\
\hline & 100 & 29 & $\mathrm{p}=0.07$ \\
\hline \multicolumn{4}{|l|}{ Number of foci } \\
\hline 2 & 72.4 & 21 & \\
\hline 3 & 17.3 & 5 & \\
\hline \multirow[t]{2}{*}{$\geq 4$} & 10.3 & 3 & \\
\hline & 100 & 29 & - \\
\hline \multicolumn{4}{|l|}{ Laterality } \\
\hline Contralateral & 72.4 & 21 & \\
\hline \multirow[t]{2}{*}{ Unilateral } & 27.6 & 8 & \\
\hline & 100 & 29 & - \\
\hline \multicolumn{4}{|l|}{ Thyroiditis } \\
\hline Yes & 24.1 & 7 & \\
\hline \multirow[t]{2}{*}{ No } & 75.9 & 22 & \\
\hline & 100 & 29 & $\mathrm{p}=0.64$ \\
\hline \multicolumn{4}{|l|}{ Goiter } \\
\hline Yes & 65.5 & 19 & \\
\hline \multirow[t]{2}{*}{ No } & 34.5 & 10 & \\
\hline & 100 & 29 & $\mathrm{p}=0.01$ \\
\hline Lymph nodal metastasis & & & \\
\hline Yes & 15.2 & 5 & \\
\hline No & 84.8 & 24 & \\
\hline & 100 & 29 & $\mathrm{p}=0.41$ \\
\hline
\end{tabular}


Although studied for several decades, the incidence and the exact dissemination of multifocal disease, more specifically, contralateral disease, are not yet well established. One of the reasons is that patients submitted to lobectomy does not have information about the contralateral lobe. Multifocality, according to literature, can occur between 18 and 87\% [6-12], and the rate of contralateral disease estimated at around 13 to $56 \%$ [24, 25]. In a more recent study, Pitt et al., identified a rate of $29 \%$ for the contralateral disease in a cohort of 228 patients [12]. In our study, one in three patients $(33.3 \%)$ presented more than one focus of cancer in the thyroid gland. Of these patients, the majority presented contralateral or bilateral disease $(72.4 \%)$, being the contra laterality rate of $24 \%$. Therefore, it is inferred that lobectomy could lead $24 \%$ of patients with thyroid cancer to inadequate treatment.

The multifocal disease was considered, for years, as the result of the intra-glandular dissemination of the primary tumor and so related to a more aggressive disease, with increased risk of locoregional recurrence, as well as lymph node metastasis and distant metastasis [6-9]. The recent advances in molecular genetics allowed the researchers to challenge this intra-glandular spread. In recent years, some studies have explored the genetic origin of multifocal thyroid papillary carcinoma. McCarthy et al., [26], in 2006, and Jovanovic et al., [27], in 2008, presented a molecular evidence for the same clonal origin of multifocal papillary thyroid cancers. In contrast, Shattuck et al., [28], in 2005, showed that in 50\% of cases with multifocal disease the tumor foci were independent, most of them microcarcinomas. The follicular carcinoma is considered as a unifocal tumor that spreads in the bloodstream, in opposition to the intra-glandular spread. In consonance with literature data, all patients in this study with multifocal disease had the second focus less than $1 \mathrm{~cm}$, and only one patient presented lesions type T1b. In relation to the histological type, almost all patients presented papillary carcinoma. No patient with follicular carcinoma, in our study, presented multicentric disease.

As virtually all patients with tumors greater than $1 \mathrm{~cm}$ are submitted to total thyroidectomy, followed or not by ablation with radioactive iodine, the clinical implication on the presence or absence of multifocal thyroid carcinoma may be less important. Although the multicentricity does not appear in any system of staging for thyroid malignant tumors, there is an association established among multifocality and local or locoregional recurrence, lymph node metastasis and distant metastasis. Therefore, the presence of multifocality classifies patients at a higher risk group, which implies a treatment and follow up more rigorous [22].

Previous studies have showed that patients with multifocal welldifferentiated thyroid carcinoma, have relatively high rates of extra thyroid extension (21\%), lymph node involvement $(26 \%)$ and distant metastasis (3\%) [29-31]. Our study showed an association of multifocal cancer of the thyroid with extra-thyroid extension in $41 \%$ of patients and with lymph node metastasis in $15.2 \%$ of the cases.

According to Kawaura et al., [32], patients with multicentric thyroid carcinoma show some association with goiter and thyroiditis, although not in a statistically significant way. In our study, the presence of goiter was associated to multicentric thyroid cancer in $65.5 \%$ of the patients $(n=19, \mathrm{p}=0.01)$ and $25 \%$ $(n=7)$ of patients with multicentric disease presented thyroiditis.
Although we found no data in the literature comparing the presence of thyroid cancer multicentricity and tumor capsule, we found, in our study, a statistically significant association between tumors not encapsulated and more than one focus of thyroid cancer $(\mathrm{p}=0.04)$.

A comprehensive analysis performed by Ito and Miyauchi [33] suggested that, in some cases of low risk papillary microcarcinoma, incidentally identified on imaging exams, patients can only be observed. In addition, Bilimoria et al., in their study of 43,227 patients submitted to total thyroidectomy and 8,946 patients submitted to lobectomy for differentiated thyroid carcinoma, found differences in the rates of local recurrence and overall survival only for tumors larger than $1 \mathrm{~cm} \mathrm{[34].} \mathrm{These} \mathrm{studies}$ suggest that the presence of multifocal papillary microcarcinomas not demonstrates an apparent clinical significance and therefore the total thyroidectomy is not indicated for all patients, based in multifocality. However, we believe that, as demonstrated in our analysis, a prevalence of $33 \%$ of multifocal disease and, of these, $72 \%$ with contralateral disease, should not be ignored, and surgeons must discuss about the extension of thyroidectomy with their patients, even in the presence of microcarcinomas.

In addition, patients with papillary microcarcinoma and multifocal lesions have a relative indication for ablation with radioactive iodine, better performed after a total thyroidectomy. The benefits of postoperative radioactive iodine include better monitoring and is associated with the reduction of local recurrence and mortality [35].

In the last decade, the guidelines for the histological analysis of thyroid gland by pathologists recommended that the sections of the gland should be representative only [36]. In our institution, the pathologists follow this recommendation, emphasizing more suspicious areas, either at macro or microscopy during the specimens processing.

According to data from the literature, patients with thyroid multicentric microcarcinoma have a higher rate of recurrence and metastasis (lymph nodal and distant) in comparison with unifocal disease. Therefore, these patients should be treated as a high risk group [37].

The retrospective analysis and transverse design for the pathological reports were one of the limitations of our study. The fact that the majority of the cases of multifocal malignant thyroid disease was diagnosed only in reports of histology (rarely in the preoperative exams) also characterizes a limiting factor for comparative prospective studies. Possibly, studies with prospective view, analyzing recurrence and overall survival rates for patients diagnosed with multifocal disease of the thyroid gland, may have greater importance in the evaluation of these patients, although difficult to carry out, due to the somehow good evolution of welldifferentiated thyroid carcinomas.

\section{Conclusion}

We evidenced, in our study, that presence of two or more foci of thyroid cancer were identified in $33 \%$ of patients, being more prevalent in females $(79.3 \%, \mathrm{n}=23)$. Of the 11 men with thyroid cancer, $54.5 \%(n=6)$ presented multifocal disease. The rate of 
contra laterality in our study was $24 \%$. In a statistically significant way, $68.9 \%(n=20, p=0.04)$ of patients with multifocal disease had no capsule delimiting the thyroid tumors and $65.5 \%(n=19$, $\mathrm{p}=0.01$ ) of patients with multicentric disease had goiter associated with thyroid cancer.

\section{References}

[1]. Davies L, Welch HG (2006) Increasing incidence of thyroid cancer in the United States, 1973-2002. JAMA. 295: 2164-2167.

[2]. Instituto Nacional de Câncer (INCA), 2016. http://www.inca.gov.br/estimativa/2016/sintese-de-resultados-comentarios.asp

[3]. Hodgson NC, Button J, Solorzano CC (2004) Thyroid cancer: is the incidence still increasing? Ann Surg Oncol. 11: 1093-1097.

[4]. National Comprehensive Cancer Network (NCCN), 2009. http://www. nccn.org.

[5]. Haugen BR, Alexander EK, Bible KC, Doherty GM, Mandel SJ, et al., (2016) 2015 American Thyroid Association Management guidelines for adult patients with thyroid nodules and differentiated thyroid cancer - The American Thyroid Association guidelines task force on thyroid nodules and differentiated thyroid cancer. Thyroid. 26(1): 1-133.

[6]. Iida F, Yonekura M, Miyakawa M (1969) Study of intraglandular dissemination of thyroid cancer. Cancer. 24(4): 764-771.

[7]. Carcangiu ML, Zampi G, Rosai J (1985) Papillary thyroid carcinoma: a study of its many morphologic expressions and clinical correlates. Pathol Annu. 20(1): 1- 44.

[8]. Tscholl-Ducommun J, Hedinger CE (1982) Papillary thyroid carcinomas. Morphology and prognosis. Virchows Arch A Pathol Anat Histol. 396(1): $19-39$.

[9]. Katoh R, Sasaki J, Kurihara H, Suzuki K, lida Y, et al., (1992) Multiple thyroid involvement (intraglandular metastasis) in papillary thyroid carcinoma. A clinicopathologic study of 105 consecutive patients. Cancer. 70: $1585-1590$.

[10]. Hawk WA, Hazard JB (1976) The many appearances of papillary carcinoma of the thyroid. Cleve Clin Q. 43: 207-215.

[11]. Russel WO, Ibanez ML, Clark RL, White EC (1963) Thyroid carcinoma classification, intraglandular dissemination, and clincopathological study based upon whole organ sections of 80 glands. Cancer. 16: 1425-1460.

[12]. Pitt SC, Sippel RS, Chen H (2009) Contralateral papillary thyroid cancer: does size matter? Am J Surg. 197(3): 342-347.

[13]. Sand J, Palkola K, Salmi J (1996) Surgical complication after total thyroidectomy and resections for differentiated thyroid carcinoma. Ann Chir Gynaecol. 85(4): 305-308

[14]. Tollefsen HR, Shah JP, Huvos AG (1972) Papillary carcinoma of the thyroid. Recurrence in the thyroid gland after initial surgical treatment. Am J Surg. 124(4): 468-72.

[15]. De Jong SA, Demeter JG, Lawrence AM, Paloyan E (1992) Necessity and safety of completion thyroidectomy for differentiated thyroid carcinoma. Surgery. 112(4): 734-737.

[16]. De Groot LJ, Kaplan EL (1991) Second operations for "completion" of thyroidectomy in treatment of differentiated thyroid cancer. Surgery. 110(6): 936-940.

[17]. Hoie J, Stenwing E, Brennhoud IO (1988) Surgery in papillary thyroid carcinoma: a review of 730 patients. J Surg Oncol. 37(3): 147-151.

[18]. Scheumann GF, Seeliger H, Musholt TJ, Gimm O, Wegener G, et al., (1996) Completion thyroidectomy in 131 patients with differentiated thyroid carcinoma. Eur J Surg. 162(9): 677-84.

[19]. Ward PH (1986) The surgical treatment of thyroid cancer. The primary disease. Arch Otolaryngol Head Neck Surg. 12(11): 1204-1206.

[20]. Girelli ME, Busnardo B, Amerio R, Scotton G, Casara D, et al., (1985) Serum thyroglobulin levels in patients with well-differentiated thyroid cancer during suppression therapy: study on 429 patients. Eur J Nucl Med. 10(56): 252-254

[21]. Rossi RL, Cady B, Silverman ML, Wool MS, Horner TA (1986) Current results of conservative surgery for differentiated thyroid carcinoma. World J Surg. 10(4): 612-22.

[22]. Mazzaferri EL, Jhiang SM (1994) Long-term impact of initial surgical and medical therapy on papillary and follicular thyroid cancer. Am J Med. 97(5): $418-428$.

[23]. Grigsby PW, Reddy RM, Moley JF, Hall BL (2006) Contralateral papillary thyroid cancer at completion thyroidectomy has no impact on recurrence or survival after radioiodine treatment. Surgery. 140(6) : 1043-1047.

[24]. Schlönberger J, Marienhagen J, Agha A, Rozeboom S, Eilles C, et al., (2007) Papillary microcarcinoma and papillary cancer of the thyroid $<$ or $=1 \mathrm{~cm}$ : modified definition of the $\mathrm{WHO}$ and the therapeutic dilemma. Nuklearmedizin. 46(4): 115-120.

[25]. Pasieka JL, Thompson NW, McLeod MK, Burney RE, Macha M (1992) The incidence of bilateral well-differentiated thyroid cancer found at completion thyroidectomy. World J Surg. 16(4): 711-716.

[26]. McCarthy RP, Wang M, Jones TD, Strate RW, Cheng L (2006) Molecular evidence for the same clonal origin of multifocal papillary thyroid carcinomas. Clin Cancer Res. 12: 2414-2418.

[27]. Jovanovic L, Delahunt B, McIver B, Eberhardt NL, Grebe SK ( 2008) Most multifocal papillary thyroid carcinomas acquire genetic and morphotype diversity through subclonal evolution following the intra-glandular spread of the initial neoplastic clone. J Pathol. 215(2): 145-154.

[28]. Shattuck TM, Westra WH, Ladenson PW, Arnold A ( 2005) Independent clonal origins of distinct tumor foci in multifocal papillary thyroid carcinoma. N Engl J Med. 352(23): 2406-2412.

[29]. Chow SM, Law SC, Chan JK, Au SK, Yau S, et al., (2003) Papillary microcarcinoma of the thyroid-prognostic significance of lymph node metastasis and multifocality. Cancer. 98(1): 31-40.

[30]. Pellegriti G, Scollo C, Lumera G, Regalbuto C, Vigneri R, et al., (2004) Clinical behavior and outcome of papillary thyroid cancers smaller than $1.5 \mathrm{~cm}$ in diameter: study of 299 cases. J Clin Endocrinol Metab. 89(8): 3713-3720.

[31]. Nam-Goong IS, Kim HY, Gong G, Lee Hk, Hong SJ, et al., (2004) Ultrasonography-guided-fine-needle aspiration of thyroid incidentaloma: correlation with pathological findings. Clin Endocrinol (Oxf). 60(1): 21-28.

[32]. Kawaura M, Pathak I, Gullane PJ, Mancer K, Irish J, et al., (2001) Multicentricity in papillary thyroid carcinoma: analysis of predictive factors. J Otolaryngol. 30(2): 102-105.

[33]. Ito Y, Miyauchi A (2009) Prognostic factors and therapeutic strategies for differentiated carcinomas of the thyroid. Endocr J. 56(2): 177-192.

[34]. Bilimoria KY, Bentrem DJ, Ko CY, Stewart AK, Winchester DP, et al., (2007) Extent of surgery affects survival for papillary thyroid cancer. Ann Surg. 246(3): 375-381.

[35]. Reiners C, Dietlein M, Luster M (2008) Radio-iodine therapy in differentiated thyroid cancer: indications and procedures. Best Pract Res Clin Endocrinol Metab. 22(6): 989-1007.

[36]. Haggi M, Yacov S, David H, Ido M, Ilana A, et al., (2011) Multifocality in well-differentiated thyroid carcinomas calls for total thyroidectomy. Am J Surg. 201(6): 770-775.

[37]. Jen DL, Tzu-Chieh C, Chuen H, Sheng-Fong K (2009) High Recurrent Rate of Multicentric Papillary Thyroid Carcinoma. Ann Surg Oncol. 16(9): 2609-2616. 